\title{
DOCTORATES CONFERRED IN 1960
}

The following are among those who received doctorates in the mathematical sciences and related subjects from universities in the United States and Canada during 1960. In each case when available, the university, the month in which the degree was conferred, minor subjects (other than mathematics), and title of dissertation are given. 309 names are listed.

R. H. Abraham, University of Michigan, June, Discontinuities in general relativity.

R. D. Adams, University of Minnesota, June, minor in Physics, $I_{p}$ density of solutions to parabolic and related equations on space time surfaces.

Sidney Addelman, Iowa State University, November, Fractional factorial plans.

D. E. Amos, Oregon State College, June, minor in Chemical Engineering, Application of the Wiener-Hopf technique to half plane diffraction of cylindrical waves.

$\mathrm{K}$. W. Anderson, University of Illinois, June, Midpoint local uniform convexity, and other geometric properties of Banach spaces.

M. A. Arkowitz, Cornell University, June, The generalized Whitehead product.

Michael Artin, Harvard University, June, On Enriques' surfaces.

H. R. Axelrod, New York University, June, minor in Biology, Mathematical basis for solution of medical and dental biostatistical problems.

A. E. Babbitt, Jr., Columbia University, June, Finitely generated pathological extensions of difference fields.

O. P. Bagai, University of British Columbia, May, Multiple comparison methods and certain distributions arising in multivariate statistical analysis.

R. E. Barlow, Stanford University, October, Applications of semiMarkov processes to counter and reliability problems.

B. H. Barnes, Michigan State University, December, Structure of automata.

L. E. Batson, University of Texas, January, minor in Physics, On inversion of the Laplace transformation by means of a step-function.

Sister Marion Beiter, Catholic University of America, February, minor in Physics, Coefficients in the cyclotomic polynomial for a number with at most three distinct odd primes in its factorization.

Geneva Grosz Belford, University of Illinois, June, minor in Physics, Computer logic programs. 
E. R. Berkson, University of Chicago, August, I. Generalized diagonable operators. II. Some metrics on the subspaces of a Banach space.

S. A. Bessler, Stanford University, June, Theory and applications of the sequential design of experiments, $k$-actions and infinitely many experiments.

Andrzej Bialynicki-Birula, University of California, Berkeley, June, On automorphisms and derivations of simple rings with minimum condition.

R. J. Bickel, University of Pittsburgh, May, An investigation of properties of a scale of Abel type summability methods.

L. N. Bidwell, University of Pennsylvania, June, Regionally almost periodic transformation groups.

J. H. Billings, University of Maryland, June, Extensions of the Laplace cascade method.

R. G. Bilyeu, University of Kansas, October, minor in Physics, Perturbation of an autonomous differential equation with a parameter.

J. J. Birch, University of California, Berkeley, September, $A p$ proximations for the entropy for functions of Markov chains.

F. T. Birtel, University of Notre Dame, August, Banach algebras of multipliers.

G. R. Blakely, University of Maryland, June, Partitions and power series.

T. K. Boehme, California Institute of Technology, June, Operational calculus and the finite part of divergent integrals.

R. A. Bonic, Yale University, June, The involution in group algebras.

J. R. Borsting, University of Oregon, June, Limit theorems for censored data.

J. J. Bowers, Carnegie Institute of Technology, June, On symmetric means and their applications.

R. S. Brand, Brown University, June, The collapse of a spherical cavity in a compressible liquid.

Mildred Jeannette Brannon, University of Illinois, February, minor in Musicology, Rotations in locally bounded linear metric spaces which are not locally convex.

J. D. Brooks, University of Southern California, June, minor in Physics, Second order dissipative systems.

R. R. Brown, University of California, Los Angeles, August, Solution of boundary value problems using non-uniform grids.

Judith Brostoff Bruckner, University of California, Los Angeles, June, Triangulations of bounded distortion in the classification theory of Riemann surfaces. 
R. E. Bryan, Yale University, June, Geodesic winding on Riemannian planes.

J. D. Buckholtz, University of Texas, August, Concerning polynomial sequences and the distribution of their zeros.

Eugene Butkov, McGill University, May, Spin-orbit potentials of nucleons.

B. R. Buzby, Indiana University, June, Integral equivalence of quadratic forms over local fields with $|2|<l$.

Mary Katherine Huggin Cabell, University of Virginia, June, Mappings with a multiplicity function.

T. W. Cairns, Oklahoma State University, May, A generalized derivative.

W. V. Caldwell, University of Michigan, February, Vector spaces of light interior orientation-preserving $C^{\prime}$ functions.

D. G. Cantor, University of California, Los Angeles, August, On sets of algebraic integers whose remaining conjugates lie in the unit circle.

F. W. Carroll, Purdue University, January, On some classes of noncontinuable analytic functions; difference properties for some classes of functions on locally compact groups.

G. D. Chakerian, University of California, Berkeley, September, Integral geometry in the Minkowski plane.

S. U. Chase, University of Chicago, March, Homological properties of certain rings and modules.

S. D. Chatterji, Michigan State University, June, Martingales of Banach-valued random variables.

C. H. Chicks, University of Oregon, June, Periodic automorphisms on Banach algebras.

I. F. Christensen, Catholic University of America, June, minor in Philosophy and Psychology, Some extensions of a theorem of Marcinkiewicz.

F. L. Cleaver, Tulane University, August, On coverings of fourspace by spheres.

R. F. Cogburn, University of California, Berkeley, January, Asymptotic properties of stationary sequences.

S. H. Coleman, University of Virginia, June, Integration in infinite product spaces.

F. B. Correia, University of Colorado, June, minor in Physics, $A$ theory of primes.

C. G. Costley, University of Illinois, June, Singular nonlinear integral equation with complex valued kernels of type $N$.

R. C. Courter, University of Wisconsin, January, Maximal commutative algebras of linear transformations. 
G. A. Craft, Ohio State University, August, A transformation theory for multiplicity functions.

R. J. Crittenden, Massachusetts Institute of Technology, February, Conjugate and minimum points on Riemannian manifolds.

G. J. Culler, University of California, Los Angeles, January, Polar decomposition and boundary value problems for matrix differential equations.

G. L. Curme, University of Illinois, February, minor in Economics, Perron summability as related to Denjoy type quasi analytic functions.

T. B. Curtz, Yale University, June, A class of third order ordinary differential equations.

E. C. Dade, Princeton University, June, Multiplicity and monoidal transformations.

R. B. Darst, Louisiana State University, August, On measures and measurability.

H. T. David, University of Chicago, March, The sample mean among the order statistics.

L. C. Dean, Jr., Iowa State University, June, minor in Physics, Nonlinear hyperbolic partial differential equation with small parameter.

E. I. Deaton, University of Texas, August, Solutions of a system of two nonlinear partial differential equations of the first order, with accessory boundary conditions.

Philippe Dennery, Columbia University, On conservation of probability in the Lee model.

Betty Charles Detwiler, University of Kentucky, August, $A$ variational method for functions convex in the direction of the imaginary axis and related functions.

R. S. DeZur, University of Oregon, June, Homomorphisms on multiplicative semi-groups of continuous functions on a compact space.

R. N. D'heedene, Harvard University, March, minor in Electronics, Limit sets for nth order ordinary differential equations.

M. R. Dorff, Iowa State University, June, Large and small sample properties of estimators for a linear functional relation.

A. C. Downing, Jr., University of Michigan, June, On the convergence of steady state multiregion diffusion calculations.

R. D. Driver, University of Minnesota, August, minor in Electrical Engineering, Delay-differential equations and an application to a two-body problem of classical electrodynamics.

S. D. Dubey, Michigan State University, June, Contributions to statistical theory of life testing and reliability.

J. R. Duffett, Virginia Polytechnic Institute, June, System reliabilities from component reliabilities. 
Marguerite Elizabeth Dunton, University of Colorado, June, Some contributions to the theory of diophantine equations.

D. E. Dupree, Auburn University, August, Existence and uniqueness of interpolating rational functions.

A. L. Duquette, University of Colorado, August, The analogue of the Pisot-Vijayaraghavan numbers in fields of formal power series.

P. L. Duren, Massachusetts Institute of Technology, June, minor in Physics, Spectral theory of a class of non-selfadjoint infinite matrix operators.

T. A. Dwyer, Case Institute of Technology, June, minor in Physics, Numerical analysis and nonlinear network problems.

J. A. Dyer, University of Texas, August, minor in Physics, On the consequences of momentum conservation laws in a gravitational theory of the Whitehead type.

C. H. Edwards, Jr., University of Tennessee, December, Concentric tori in the three-sphere.

L. C. Eggan, University of Oregon, June, On diophantine approximations.

C. C. Elgot, University of Michigan, February, Decision problems of finite automata design and related arithmetics.

B. E. Ellison, University of Chicago, June, A multivariate k-population classification problem.

J. A. Ernest, University of Illinois, February, Central intertwining numbers for representations of finite groups.

D. J. Eustice, Purdue University, January, Summability of orthogonal series.

Leonard Evens, Harvard University, June, The cohomology ring of a finite group.

J. A. Ferling, University of Southern California, June, A nonlinear eigenvalue problem for harmonic functions.

K. M. Ferrin, University of California, Los Angeles, June, Multiple decision procedures for normal populations.

R. I. Fields, Virginia Polytechnic Institute, June, Estimation with samples drawn from different but parametrically related distributions.

A. M. Fink, Iowa State University, February, minor in History of Science, Almost periodic points in topological transformation semigroups.

Betty J. Isaacs Flehinger, Columbia University, November, $A$ general model for the reliability analysis of systems under various preventive maintenance policies.

L. D. Fountain, University of Nebraska, August, minor in Physics, The boundary value problem for an ordinary nonlinear differential equation of second order. 
Stanley Frank, University of Florida, February, minor in Education, Certain cyclic involutory mappings on hyperspace surfaces.

D. A. Freedman, Princeton University, October, Mixtures of stochastic processes.

M. L. Freimer, Harvard University, June, Truncated policies in dynamic programming.

A. H. Frey, Jr., University of Washington, June, Studies on amenable semigroups.

P. J. Freyd, Princeton University, June, Functor theory.

Yoichiro Fukuda, University of California, Los Angeles, June, Estimation problems in inventory control.

J. B. Garner, Auburn University, June, Linear differential systems with two-point and three-point boundary conditions.

E. D. Gaughan, University of Kansas, October, minor in Physics, Generalized derivatives.

D. W. Gaylor, North Carolina State College, May, The construction and evaluation of some designs for the estimation of parameters in random models.

C. W. Gear, University of Illinois, June, Singular shock intersections in plane flow.

Q. K. Ghori, University of British Columbia, May, minor in Physics, On the equations of motion of mechanical systems subject to nonlinear nonholonomic constraints.

J. D. Gilbert, Auburn University, August, On subdirect products.

S. C. Gitier, Princeton University, April, Cohomology operations with bundles of coefficients.

Orville Goering, Iowa State University, June, minor in Physics, Dependence of the solution of a Goursat problem on the characteristic data.

Ruth Zwerling Gold, Columbia University, June, Inference about Markov chains with nonstationary transition probabilities.

A. B. Gray, Jr., New Mexico State University, January, minor in Physics, Infinite symmetric groups and monomial groups.

D. A. Greenberg, Columbia University, Theory of the hyperfine anomalies of deuterium, tritium and helium ${ }^{3+}$.

Martin Greendlinger, New York University, February, Dehn's algorithm for the word problem.

J. E. Grizzle, North Carolina State College, May, minor in Animal Industry, Application of the logistic model to analyzing categorical data.

B. I. Gross, University of Pennsylvania, February, Groups of formal analytic transformations.

Arnold Grudin, University of Colorado, June, minor in Philosophy, Zeros of successive derivatives of entire functions. 
S. K. Gupta, Case Institute of Technology, June, $A$ theory of adjusting parameter-estimates in decision models.

W. L. Hafley, North Carolina State College, May, minor in Forestry, Some comparisons of sensitivities for two methods of measurement.

Maurice Hanan, Carnegie Institute of Technology, June, Oscillation criteria for third-order linear differential equations.

V. R. Hancock, Tulane University, August, Commutative Schreier extensions of semigroups.

E. R. Hansen, Stanford University, October, On Jacobi methods and Block-Jacobi methods for computing matrix eigenvalues.

D. L. Hanson, Indiana University, June, Contributions to decision theory, ergodic theory, and stochastic processes.

J. E. Hanson, George Washington University, February, On linear sequence spaces which permit omission and adjunction and have finite dimension modulo convergence.

M. E. Harris, Harvard University, June, Some results on a generalization of the character table of a finite group.

C. A. Harvey, University of Minnesota, December, minor in Physics, Existence of periodic solutions of the differential equation $x^{\prime \prime}+g(x)=p(t)$.

M. P. Heble, Indiana University, June, Linear estimation of regression coefficients; orthogonal matrix polynomials and application to multidimensional weakly stationary processes; interpolation and regression.

Stevens Heckscher, Harvard University, March, A characterization of certain Banach function spaces.

Gertrude Ilse Heller, Johns Hopkins University, June, On certain non-linear operators and partial differential equations.

D. S. Henderson, Harvard University, June, Logical designs for arithmetic units.

S. W. Hess, Case Institute of Technology, June, On research and development budgeting and project selection.

P. D. Hill, Auburn University, June, Limits of discrete groups.

Heisuke Hironaka, Harvard University, June, Theory of birational blowing-ups.

C. R. Hobby, California Institute of Technology, June, The derived series of a p-group.

H. C. Hsieh, University of California, Berkeley, June, The analysis of the effect of an obstacle on the electromagnetic field in a circular cylindrical wave guide.

N.-C. Hsu, Washington University, January, On automorphisms of a splitting extension $G=(H, K ; \phi)$. 
T. C. Hu, Brown University, June, Optimum design for structures of perfectly-plastic materials.

B. E. Hubbard, University of Maryland, June, Bounds for eigenvalues of the free and fixed membrane by finite difference methods.

Taqdir Husain, Syracuse University, September, On S-spaces and the open mapping theorem.

S. Y. Husseini, Princeton University, June, On the cohomology of exact sequences of compact groups.

P. H. Hutcheson, University of Florida, August, minor in Chemistry, The use of complex variables for solving certain elasticity problems involving intersecting boundaries.

J. M. Irwin, University of Kansas, June, High subgroups of Abelian torsion groups.

J. E. Jackson, Virginia Polytechnic Institute, June, Multivariate sequential procedures for testing means.

Ronald Jacobowitz, Princeton University, June, Hermitian forms over local fields.

B. N. Jamison, University of California, Berkeley, September, $O n$ ergodic theory of Markov operators.

R. I. Jennrich, University of California, Los Angeles, Analysis of variance in the general mixed model.

H. L. Johnson, University of Minnesota, June, minor in Physics, Quadratic versus linear dependence of solutions of certain linear partial differential equations.

G. S. Jones, Jr., University of Cincinnati, August, Asymptotic behavior and periodic solutions of a nonlinear differential-difference equation.

W. L. Jones, Columbia University, November, On conjugate functionals.

C. L. Kaller, Purdue University, June, A statistical approach to the study of genetic environmental interactions.

H. M. Kamowitz, Brown University, June, Cohomology groups of commutative Banach algebras.

Julius Kane, New York University, June, minor in Physics, Part I. An accurate boundary condition to replace transition conditions at dielectric-dielectric interfaces. Part II. Radio propagation past a dielectric interface.

E. D. Kann, New York University, February, Bonnet's theorem in two-dimensional G-spaces.

J. E. Kelley, University of Michigan, June, Characterization of the closed 2-cell and of the 2-sphere without assuming compactness.

C. F. Kent, Massachusetts Institute of Technology, September, 
minor in Physics, Algebraic structure of some groups of recursive permutations.

S. A. Khabbaz, University of Kansas, June, Theorems on Abelian groups.

H.-C. Khare, McGill University, May, Positron annihilation and scattering in helium.

Masakiti Kinukawa, Northwestern University, June, Fourier series.

R. S. Kleber, State University of Iowa, June, On the problem of minimum variance and maximum probability.

Adam Kleppner, Harvard University, June, Multipliers on Abelian groups.

J. H. Klotz, University of California, Berkeley, September, Nonparametric tests for scale.

T. B. Knapp, Harvard University, March, The relatively minimal models of a rational function field.

A. G. Konheim, Cornell University, June, Some properties of a class of finite trigonometric sums.

F. J. Kosier, Michigan State University, September, On a class of non-flexible algebras.

Samuel Kotz, Cornell University, September, Exponential bound for the probability of error in discrete memoryless channels.

Kurt Kreith, University of California, Berkeley, June, The spectrum of singular elliptic operators.

B. M. Kurkjian, American University, June, General theory for asymmetrical confounded factorial experiments.

W. H. Lake, Catholic University of America, June, minor in Physics, The numerical inversion of a particular class of matrices.

L. H. Lange, University of Notre Dame, June, Non-Euclidean Cercles de Remplissage and other analogues in the unit circle to classical theorems on entire functions.

L. J. Lange, University of Colorado, August, Divergence, convergence, and speed of convergence of continued fractions $1+K\left(a_{n} / 1\right)$.

R. P. Langlands, Yale University, June, Semi-groups and representations of Lie groups.

H. J. Larson, Iowa State University, August, minor in Industrial Engineering, Sequential model building for prediction in regression analysis.

A. T. Lauria, Purdue University, January, One-dimensional retracts.

Leon LeBlanc, University of Chicago, June, Non-homogeneous and higher polyadic algebras. 
E. B. Lee, University of Minnesota, August, minor in Engineering, Methods of optimum feedback control.

L. M. Levine, New York University, June, Diffraction by an elliptic cone.

B. W. Levinger, New York University, June, A generalization of the braid group.

G. E. Lewis, New York University, February, Two methods using power series for solving analytic non-characteristic initial value problems.

J. A. Lindberg, Jr., University of Minnesota, August, On the theory of algebraic extensions of a normed algebra.

Seymour Lipschutz, New York University, February, On the braid group.

H.-C. Liu, University of Cincinnati, June, Interpolation of entire functions.

A. L. Liulevicius, University of Chicago, June, The factorization of cyclic reduced powers by secondary cohomology operations.

Stanley Locke, New York University, February, A boundary layer theory of elastic plane stress.

J. L. Locker, Auburn University, August, A statistical analysis of the propagation of rounding error.

C. A. Long, University of Illinois, June, minor in Physics, Schwartz distributions analytic in a parameter.

David Lubell, New York University, June, Distribution functions for completely additive arithmetical functions on subsequences of the natural numbers.

A. T. Lundell, Brown University, June, Obstruction theory of principal fibre bundles.

C. W. Lytle, New York University, February, Differentiators for linear second order elliptic partial differential equations.

E. B. McCue, Carnegie Institute of Technology, June, Power characteristics of the control chart for number of defects, no standard given.

J. E. McFarland, Oregon State College, June, Iterative solution of nonlinear integral equations.

R. A. McHaffey, Rutgers, The State University, June, Structure theorems for a class of lattice ordered real Banach algebras.

D. O. McKay, University of Buffalo, February, minor in Philosophy, An extension of the Staudt-Clausen and Kummer congruences for the Bernoulli numbers of higher order.

D. R. McMillan, Jr., University of Wisconsin, June, On homologically trivial 3-manifolds.

G. J. Maltese, Yale University, June, Generalized convolution algebras and spectral representations. 
John Mariani, New York University, February, Exponential solutions of linear differential equations of the second degree.

P. H. Maserick, University of Maryland, August, Half rings in linear spaces.

T. K. Matthes, Columbia University, June, Two-stage sampling procedures.

J. G. May, University of Virginia, June, Non-closed connected sets.

W. G. May, University of Virginia, June, Images of plane continua.

J. W. Meux, University of Florida, August, minor in Education, Orthogonal polynomial solutions of a class of fourth order linear differential equations.

P. E. Miles, Yale University, June, Order isomorphisms of $B^{*}$ algebras.

R. M. Mirman, Columbia University, The dispersion relations for pion production in pion nuclear collisions.

B. M. Mitchell, Brown University, June, Homological tic tac toe.

C. C. Moore, Harvard University, June, Extensions and cohomology theory of locally compact topological groups.

D. F. Morrison, Virginia Polytechnic Institute, June, The life distribution and reliability of a system with spare components.

J. F. Mount, University of California, Los Angeles, June, Some applications of Schauder's theory to the calculus of variations and numerical analysis.

K. R. Mount, University of California, Berkeley, June, Characteristic classes of algebraic vector bundles.

I. H. Mufti, The University of British Columbia, May, minor in Physics, Stability in the large of autonomous systems of two differential equations.

D. E. Myers, University of Illinois, February, An imbedding space for Schwartz distributions.

A.-A. K. Nafoosi, University of Colorado, June, Representation of any large number as the sum of thirteen squares of positive integers in arithmetical progression.

Sister Mary Redempta Nedumpilly, St. Louis University, June, minor in Physics, On a generalized Feld series.

L. W. Neustadt, New York University, February, The moment problem and weak convergence in a Hilbert space.

J. N. Newman, Massachusetts Institute of Technology, February, Linearized theory for the motion of a thin ship in regular waves.

H. H. Nickle, Columbia University, Strong-coupling treatment of a charged scalar meson field interacting with a static extended source.

R. N. van Norton, New York University, February, The spectrum of a neutron transport operator. 
R. C. O'Neil, University of Chicago, December, Fractional integration and Orlicz spaces.

D. R. Ostberg, University of California, Berkeley, September, Cohomology of groups and simple algebras.

E. H. Ostrow, University of Chicago, August, $A$ theory of generalized Hilbert transforms.

J. R. Padro, St. Louis University, June, Extension and applications of cumulative characteristic functions.

R. P. Pakshirajan, University of Oregon, June, Regular measures and stochastic processes in topological groups.

J. B. Pan, St. Louis University, June, minor in Physics, On topological semigroups.

Subramonier Parameswaran, University of Illinois, February, minor in Education, Some theorems on the growth of partition functions.

W. E. Parr, University of Maryland, June, minor in Physics, Upper and lower bounds for the capacitance of the regular solids.

C. W. Patty, University of Georgia, June, Homotopy groups of certain deleted product spaces.

K. M. Patwary, American University, June, Error and non-error models in bio-assay.

E. M. Paul, University of Illinois, October, minor in Philosophy, Density in the light of probability theory.

C. M. Pearcy, Jr., Rice University, June, On the unitary equivalence of $N$-normal operators.

J. M. Perry, University of Rochester, June, Solution of boundaryvalue problems in arbitrary sectors by use of the double Laplace transform.

M. W. Pownall, University of Pennsylvania, February, An investigation of a conjecture of Goodman.

Walter Pressman, New York University, June, Evaluation of partition functions.

W. E. Pruitt, Stanford University, June, Bilateral birth and death processes.

L. D. Pyle, Purdue University, June, The generalized inverse in linear programming.

D. E. A. Quade, University of North Carolina, June, The asymptotic power of the Kolmogorov tests of goodness of fit.

D. F. Rearick, California Institute of Technology, June, Some visibility problems in point lattices.

J. D. Reid, University of Washington, August, Invariants of torsion free groups. 
J. I. Richards, Harvard University, June, A classification of noncompact surfaces.

Wyman Richardson, University of North Carolina, August, A symptotic methods of evaluating $\int_{a}^{\infty} f(x) d x$.

Helen G. Murray Roberts, Boston University, June, Two sequential tests against cyclic trend.

Ruth Mabel Roberts, University of Pennsylvania, June, On the solvability of a second order linear homogeneous differential equation.

V. G. Robinson, Purdue University, June, A study of mathematical models of epidemic disease distributions.

Esther Rodlitz, New York University, February, Deformation of Riemann surfaces.

B. W. Romberg, University of Rochester, June, The spaces $H_{p}$ with $0<p<1$.

H. M. Rosenblatt, George Washington University, February, Multivariate experimental designs.

Azriel Rosenfeld, Columbia University, Specializations in differential algebra.

Alan Ross, Iowa State University, February, On two problems in sampling theory: unbiased ratio estimators and variance estimates in optimum sampling designs.

K. A. Ross, University of Washington, March, Studies in semigroups.

Hugo Rossi, Massachusetts Institute of Technology, February, minor in Languages, Maximality of algebras of holomorphic functions.

R. D. Ryan, California Institute of Technology, June, Fourier transforms of certain classes of integrable functions.

M. J. Saadaldin, Duke University, September, A generalized Lebesgue covering theorem.

David Sachs, Illinois Institute of Technology, January, Modulated and partition lattices.

R. C. Sacksteder, Johns Hopkins University, February, minor in Physics, Local and global properties of convex sets and hypersurfaces.

A. A. Sagle, University of California, Los Angeles, August, Malcev algebras.

P. A. Scheinok, Indiana University, June, The error on using the asymptotic variance and bias of spectrograph estimates for finite observation time.

E. M. Scheuer, University of California, Los Angeles, June, Simultaneous estimation for means or medians of dependent random variables without distribution assumptions.

A. J. Schwartz, Wayne State University, August, The geometric theory of non-compact transformation groups. 
Lorraine Schwartz, University of California, Berkeley, September, Consistency of Bayes' procedures.

Jack Segal, University of Georgia, June, Inverse limit spaces.

Tetsundo Sekiguchi, Oklahoma State University, August, Representation theorems for summability operators and linear functionals on bounded sequences.

D. W. H. Shale, University of Chicago, June, On certain groups of operators on Hilbert space.

W. T. Sharp, Princeton University, June, Racah algebra and the contraction of groups.

Aaron Siegel, Rutgers, The State University, January, Summability $C$ of series of surface spherical harmonics.

Rajinder Singh, University of Illinois, June, minor in Economics, Existence of bounded length confidence intervals.

R. C. Singleton, Stanford University, October, Steady state properties of selected inventory models.

F. M. Sioson, University of California, Berkeley, June, Contributions to the theory of primal and independent algebras.

R. C. Smith, McGill University, May, Central three-body nuclear forces.

Ramaiyengar Sridharan, Columbia University, June, Filtered algebras and representations of Lie algebras.

S. R. Srivastava, Purd ue University, June, The power of an analysis of variance test procedure involving some preliminary tests for certain incompletely specified models.

E. W. Stacy, University of North Carolina, June, An estimate of correlation corrected for attenuation and its distribution.

W. D. Stahlman, Brown University, June, The astronomical tables of Codex Vaticanus Graecus 1291.

J. G. Stampfli, University of Michigan, February, On operators related to normal operators.

H. M. Sternberg, University of Maryland, June, The solution of the characteristic and the Cauchy boundary value problems for the Bianchi partial differential equation in $n$ independent variables by a generalization of Riemann's method.

H. R. Stevens, Duke University, June, minor in Philosophy, Hurwitz product of sequences satisfying a generalized Kummer's congruence.

S. H. Storey, McGill University, May, The galvanomagnetic properties of some solids at low temperatures and high magnetic fields.

S. L. Strack, Brown University, June, Supersonic panel futter of a finite cylinder.

Charlotte Thomas Striebel, University of California, Berkeley, 
January, Efficient estimation of regression parameters for certain second order stationary processes.

Beauregard Stubblefield, University of Michigan, February, minor in Philosophy, Some compact product spaces which cannot be imbedded in Euclidean n-space.

Mudomo Sudigdomarto, University of Illinois, February, minor in Physics, $A$ representation theory for the Laplace transform of vectorvalued functions.

Shashikala Sukhatme, Michigan State University, September, Asymptotic theory of some nonparametric tests.

D. W. Swann, Stanford University, June, Applications and extensions of the method of Wiener and Hopf for the solution of singular and non-singular integral and integro-differential equations.

R. H. Szczarba, University of Chicago, August, Homology of twisted cartesian products.

R. J. Talham, Rensselaer Polytechnic Institute, January, Directional receivers in correlation detection.

S. G. Tellman, University of Washington, June, Abelian groups with proper isomorphic quotient groups.

Peter Terwey, Jr., Texas Agricultural and Mechanical College, May, minor in Physics, Some aspects of gas dynamics in a closed region.

R. C. Thompson, California Institute of Technology, June, Commutators in the special and general linear groups.

L. J. Tick, Columbia University, September, minor in Sociology, Contributions to theory and application of random processes in fuid mechanics.

T. W. Ting, Indiana University, June, Fracture of closed circular pipes under internal pressure and axial tension.

R. J. Troyer, Indiana University, September, Multilinear algebra in Abelian categories.

E. J. Tully, Jr., Tulane University, June, Representation of a semigroup by transformations of a set.

R. L. Van de Wetering, Stanford University, October, On the motions of particles in Euclidean and non-Euclidean spaces under certain conservative force fields.

F. S. Van Vleck, University of Minnesota, August, Bifurcation of an invariant manifold from a periodic solution of a differential system.

K. Varadarajan, Columbia University, June, Dimension, category and $K(\pi, n)$ spaces.

H. M. Wadsworth, Jr., Western Reserve University, June, $A$ stochastic theory of documentation. 
J.-K. Wang, Stanford University, January, Multipliers of commutative Banach algebras.

M. T. Wasan, University of Illinois, June, Sequential estimation of a binomial parameter.

J. R. Webb, University of Texas, August, minor in Physics, $A$ Hellinger integral representation for bounded linear functionals.

J. T. Webster, North Carolina State College, July, A decision procedure for the inclusion of an independent variate in a linear estimator.

D. F. Wehn, Yale University, June, Limit distributions on Lie groups.

P. M. Weichsel, California Institute of Technology, June, $A d e-$ composition theory for finite groups with applications to p-groups.

F. W. Weiler, Ohio State University, June, On the T-Jacobian.

G. G. Weill, University of California, Los Angeles, January, Reproducing kernels and orthogonal kernels for analytic differentials on Riemann surfaces.

R. R. Welland, Purdue University, June, Local integrability in $\sigma$-finite measure spaces and Köthe spaces.

Roy Westwick, University of British Columbia, May, minor in Physics, Linear transformations on Grassmann product spaces.

T. A. Willke, Ohio State University, August, $A$ class of multivariate rank statistics.

J. C. Wilson, Case Institute of Technology, June, Analysis of concepts of differentiability on algebras.

D. M. G. Wishart, Princeton University, October, Augmentation techniques in the theory of queues.

W. W. Wolman, University of Rochester, June, A problem in the design and analysis of experiments with correlated observations.

T.-C. Woo, Brown University, June, Fundamental solutions for small deformations superposed on finite biaxial extension of an elastic body.

W. B. Woolf, University of Michigan, February, Radial cluster sets and the distribution of values of meromorphic functions.

J. Z.-T. Yao, University of Chicago, June, Moore-Catan theorems and Leray-Serre theorem.

Bohyun Yim, Brown University, June, Supersonic flow past double wedge wings with variable thickness.

N. D. Ylvisaker, Stanford University, January, On time series analysis and reproducing kernel spaces.

P. J. Zwier, Purdue University, August, Homology and cohomology from rings of functions. 